\title{
Guadalupe Pinzón Ríos y Flor Trejo Rivera (coords.), El Mar: Percepciones, lecturas y contextos. Una mirada cultural a los entornos marítimos, Universidad Nacional Autónoma de México, Instituto Nacional de Antropología e Historia, 2015, 412 pp.
}

\author{
Rosa Elba Rodríguez Tomp \\ rert@uabcs.mx \\ Universidad Autónoma de Baja California Sur
}

Fecha de Recepción: 13 - noviembre - 2016

Fecha de Aceptación: 08 - enero - 2017

Para entender cabalmente el propósito central de la obra que aquí se reseña es necesario hacer unos apuntes con respecto a esa mirada cultural que promete el título, rico, por cierto, en matices, información y estilos de discurso, pero coherente y bien logrado a partir de una unidad de análisis que atraviesa los trabajos de todos los que en la obra intervienen: la cultura.

Es ampliamente conocido en el medio académico el cúmulo de discusiones y trabajos que en los últimos años han abordado, desde distintos ángulos, el tema de la cultura, y que existen cientos de definiciones del término. De todas esas posibilidades de anclaje, me ha parecido pertinente anotar algunos de los aspectos de este fascinante mundo del quehacer humano que lo convierten en un referente adecuado para incluir, en un solo libro, discusiones que involucran asuntos tan variados como la infraestructura de un puerto, las creencias religiosas que profesaron comunidades americanas antes y después de haber sido sojuzgadas por el imperio español, saberes que se transmitieron en la forma de cartas de navegación a partir de la necesidad de recorrer con el menor número de contratiempos posible las extensas superficies del mar que se iban descubriendo, contactos comerciales entre distintas regiones aparentemente lejanas e incomunicadas, o estrategias defensivas y ofensivas de las potencias que luchaban por el dominio de esa misteriosa extensión que une a todos los continentes.

La cultura es un referente adecuado para esta tarea porque, en su concepción simbólica, ${ }^{1}$ abarca el vasto conjunto de formas en las que la humanidad, a través de la historia, ha organizado sus modos de dar sentido al mundo que habita. Existen, por supuesto, análisis que hacen hincapié en las características económicas o políticas que han desarrollado distintas sociedades, pero desde la mirada cultural, son las articulaciones y combinaciones de símbolos y su significado, lo que hace que esta dimensión constitutiva de lo social se convierta en un campo tan rico y diverso para el análisis. En ese sentido, un mapa, tanto como un faro o un conjunto de conchas de moluscos pueden ser abordados como indicios de símbolos y códigos con los que, en una época, un grupo de hombres y

\footnotetext{
${ }^{1}$ Esta forma de abordar a la cultura, que provee de un campo de análisis específico y relativamente homogéneo, ha sido desarrollada, entre otros, por Clifford Geertz (La interpretación de las culturas, Barcelona, Gedisa, 1992) y John B. Thompson (Ideología y cultura moderna, México, Universidad Autónoma Metropolitana-Xochimilco, 1998).
} 
mujeres se enfrentaron a una realidad determinada, la interpretaron y tomaron acciones para hacerla suya.

El copioso conjunto simbólico que el texto presenta, es sólo una muestra de la formidable diversidad de las representaciones y prácticas que podemos encontrar relacionadas con el inmemorial vínculo entre el ser humano y el mar. Desde sus orígenes, la humanidad debió percibir en el ambiente marino una frontera, una vía de acceso a nuevos territorios, una fuente de inspiración o de miedos paralizantes, o un mundo de posibilidades de expansión. El conjunto de trabajos que aparecen en la obra, producto de otras tantas aproximaciones de esta polifacética relación, abarcan un marco temporal que va desde los primeros horizontes culturales de los pueblos originarios del continente americano hasta algunos de los estilos de relacionarse con el mar más recientes; lo cual hace que, de título en título, tengamos que hacer un salto imaginativo que a veces resulta un poco difícil, pero el tener en mente esta singularidad de los mundos de significado nos ayuda en el tránsito. También resulta de mucha ayuda la división que las coordinadoras de la obra han hecho de los textos participantes en cuatro grandes bloques, titulado el primero "Percepciones del mar, puertos y entornos marítimos", "Cartografía marítima” el segundo, "Frontera marítima y vínculos comerciales", el tercero y "El entorno marítimo como medio de vida y comunicación” el último. No puedo dejar de pensar, sin embargo, en que debe de haber sido problemático situar a cada una de las participaciones en su lugar dentro de cada bloque, puesto que cada una, a su modo, nos habla de esta construcción contradictoria y fascinante de su relación con el medio marino por parte de una comunidad específica.

Dicho esto paso a referir algunos de los aspectos que llamaron mi atención sobre cada uno de los capítulos. En la primera parte encontramos cuatro textos cuyo núcleo aglutinador lo constituyen las percepciones del mar que distintos pueblos tuvieron y que han sido interpretadas a partir de diversos vestigios. Patrik Johansson, por ejemplo, rastrea en la lengua náhuatl, y en las fuentes escritas que permiten atisbar en el universo simbólico de los antiguos habitantes de lo que hoy es México los significados que para ellos encerraba el mar: Ilhuicatl, el agua-cielo. No puedo dejar de pensar en esa poética imagen del mar como fundamento del cielo, y en ambos, mar y cielo, como progenitores del sol, que, por cierto, ha sido compartida por muchos otros pueblos alrededor del mundo. Es también digna de mención la convergencia en el pensamiento antiguo, tanto americano como europeo, acerca de la filiación hidrológica de los ríos, las lagunas y el mar, y la explicación de la forma en la que el agua salada del lago de Texcoco llegaba a través de ductos subterráneos directamente del mar. En el texto de Blas Castellón también se hace referencia a esta creencia, lo que sorprende al autor es que se conserva en pueblos que siguen hoy día, como se hacía en tiempos prehispánicos, extrayendo sal de las tierras áridas del sur de Puebla. Tal permanencia nos recuerda los múltiples significados culturales que siguen vigentes en poblaciones que ya no reivindican identidades étnicas y que, sin embargo, mantienen lazos simbólicos con sus ancestros indígenas. La religión católica, impuesta por los conquistadores, no fue obstáculo para que se mantuvieran los profundos vínculos de la gente común con sus deidades; en el caso del mar y su producto, la sal, deidades femeninas que, según la tradición, habían llorado o excretado el mineral en el agua del mar, y que se han transformado en la virgen del Rosario de los zinacantecos, o la virgen de la Candelaria en Tlacotalpan, o en María Magdalena, que lloró la muerte de Cristo y es venerada en 
muchos lugares de extracción de sal. Emiliano Ricardo Melgar Tísoc dedica su texto a la exploración de las formas en las que los pobladores antiguos de la bahía de Chetumal, cuyo modo de vida dependía de los recursos lagunares y marinos, realizaban ofrendas de bienes que, según los contextos en los que han sido encontrados por los arqueólogos, parecen indicar tanto súplicas que los pescadores hacían a las fuerzas de la naturaleza, como pagos por los dones recibidos en una buena temporada. Melgar reflexiona sobre el hecho de que, al igual que entre los pueblos de otras latitudes, muchas veces el vestigio arqueológico, las fuentes de origen colonial y el registro etnográfico muestran coincidencias sorprendentes que hablan de la trascendencia de algunas formas simbólicas.

Mientras que los tres primeros textos dejan atisbar el universo de los mundos de significación americanos, el trabajo de Martín F. Ríos Saloma transporta a los temores y promesas que para los pobladores de la España medieval encerraba el mar. Partiendo de un contexto general de los pueblos de Europa y su relación con el mar, que variaba de acuerdo a la posición geográfica de sus asentamientos, pero también y sobre todo, de los antecedentes marineros o terrestres que su historia particular pudiese narrar, el autor establece los antecedentes de lo que fue el espectacular avance del reino de Castillla, que habiendo hecho contacto con el mar hasta el siglo XIII, a partir de la conquista de Sevilla comenzó la gesta que la llevaría en el XVI a coronarse reina del cuadrante occidental del Mediterráneo, así como del Atlántico. A partir de la lectura parece claro el porqué en el imaginario de los castellanos de esa época el medio marino estaba estrechamente relacionado con la guerra.

La segunda parte de la obra contiene dos excelentes textos en los que son las representaciones gráficas de los espacios marinos las que recuerdan que la elaboración de mapas es casi tan antigua como el ser humano, pero que los códigos utilizados para el diseño de los espacios han cambiado a través de los tiempos de manera que, para el reconocimiento de lo representado necesitamos la ayuda de elementos de interpretación que a veces se encuentran en el análisis de otros componentes de la cultura en cuestión. Guadalupe Pinzón y Carla Lois nos llevan a un periodo en el que los códigos de representación cartográfica estaban sufriendo vertiginosas modificaciones a partir de la expansión de la navegación y los conocimientos que esta práctica trajo a los marinos. Así, los espacios antes desconocidos y misteriosos, en los que antiguos cartógrafos medievales ubicaban monstruos temibles o criaturas fantásticas producto de la imaginación literaria de aquella época, fueron transformándose y reflejando el conocimiento y la experiencia de los primeros naturalistas, encargados de revelar maravillas que, aunque igual o más sorprendentes, tenían soporte en la experiencia real, y no sólo en la imaginación. Este proceso de transformación de los bestiarios cartográficos, nos dicen las autoras, no debe considerarse como una línea continua de racionalización y naturalización, sino como un camino sinuoso, lleno de contradicciones, avances y retrocesos. Tal forma de avanzar, por cierto, es la misma que podemos atestiguar en este conjunto de saberes legitimados por la experiencia y sobrevalorado en nuestros días, al que llamamos ciencia. El otro texto dedicado a la exploración de los mapas como fuentes de sentido es el de Dení Trejo Barajas, quien recorre a través de la cartografia los espacios de la Península y el golfo de California. A partir de su análisis de 6 mapas, elaborados entre 1768 y 1813 llega a conclusiones interesantes, como por ejemplo, que durante el siglo XVIII la intensificación 
en el trabajo de diseño y puesta en servicio de estos artefactos estuvo determinado por la necesidad del imperio español de controlar sus territorios de ultramar para contrarrestar los peligros del avance interesado de otras potencias, tales como Inglaterra y Rusia, y que en la serie de documentos analizados es fácil advertir que las necesidades de conocimiento y control por parte de las autoridades forzaron a los cartógrafos a una mayor precisión en el trazado de coordenadas, litorales y accidentes, recursos explotables y otros detalles que, además, eran posibles gracias a los rápidos avances de las ciencias naturales y humanas.

En la tercera parte del libro encontramos miradas al mar un tanto contradictorias, pues son a la vez cautelosas y osadas. Y es que al mar nunca se le ha podido mirar con indiferencia. Las miradas codiciosas que los europeos pusieron en los mares del mundo les aseguraron a partir del siglo XV un lugar en el desarrollo del capitalismo mercantil, pero también se convirtieron en motivo de la mayor preocupación porque las rivalidades y la violencia surgieron junto con las posibilidades de pingües ganancias. Del Mediterráneo al Atlántico y de éste al Pacífico, las disputas por el tránsito, el comercio, la piratería y su variedad legalizada a través de complicidades, que fue el corso, son los aspectos que dan sentido a este grupo de cinco trabajos: el de Yovana Celaya Nández habla de naves españolas cargadas de mercancías, que habían confiado su seguridad a los puestos de avanzada en la península de la Florida, y comenzaron a ver que desde ese territorio resultaba cada vez más difícil la defensa, pues los establecimientos que habían sido pensados para fortalecer el dominio marítimo, tenían que vérselas con diversos problemas, entre ellos los que tenían su origen en la largo y también disputado territorio peninsular, que finalmente habría de pasar a manos inglesas. Por su parte, Miguel Luque Talaván analiza el Pacífico peruano, que, como sabemos, comenzó a ser recorrido por piratas y corsarios desde que Francis Drake encontró la manera de cruzar el Estrecho de Magallanes en 1578, pero cuyos encuentros violentos entre buques de diferentes nacionalidades se hicieron cada vez más frecuentes a partir del siglo XVIII. El autor nos propone, de manera muy acertada, entender al Océano Pacífico a partir de ahí como "un espacio de negocios con sus propias dinámicas”, en el que tuvieron que implementarse políticas que muchas veces pusieron en entredicho el poder de la corona española, de las autoridades virreinales y de los comerciantes locales y foráneos, siempre a favor del control de un territorio líquido y cada vez más incontrolable.

Las propuestas de Laura Muñoz y de Karina Busto, enmarcadas también en este apartado sobre las fronteras y los vínculos tienen como escenario las luchas emprendidas para sacar adelante al proyecto de nación llamado México y las distintas maneras en las que el nuevo estado decimonónico y sus protagonistas hacían esfuerzos por encontrar caminos para el desarrollo económico en medio de los cambios del mercado mundial. En el primer texto es el Caribe y su estratégica posición el que determina las complejas interacciones que los cónsules mexicanos de la región se vieron obligados a afrontar; mientras que el segundo plantea los interesantes cambios en la dinámica comercial del puerto de Acapulco y su hinterland, una vez que quedó clausurada la ruta del galeón de Manila. La autora analiza las condiciones favorables que aparecieron para el puerto del Pacífico a partir del contagioso brote de la fiebre del oro en el ya estadounidense estado de California y el establecimiento de la ruta Panamá San Francisco, lo cual detonó una serie de eventos que 
convirtieron esa zona costera del Pacífico en centro de conexión de sus poblaciones del interior, que surtían mercancías muy diversas, con amplios espacios internacionales.

Los trabajos que conforman el último apartado del libro son tan variados e interesantes como los entornos marítimos que narran: Antonio Jaramillo Arango plantea, con el apoyo de una gran cantidad de información, la posible existencia de un extenso corredor marino mediante el cual se establecieron y cultivaron relaciones culturales y el intercambio de bienes materiales y simbólicos en la costa pacífica anterior a la conquista española, entre Mesoamérica y la región andina; Paulina Machuca, a partir del seguimiento de un personaje que actuó como escribano en la nave "Nuestra Señora de Atocha", introduce a las penurias que vivían los osados viajeros que se atrevían a hacer el largo y peligroso recorrido de la nao de Filipinas, siempre perseguidos por el fantasma de la enfermedad y las tempestades. Hugo Antonio Arciniega Ávila hace un análisis de los problemas que trajo consigo la decisión de plantar un puerto como San Blas, punta de playa de la corona española en el noroeste novohispano del siglo XVIII, en un sitio que padecía lo que el autor llama una "geografía violenta", que siempre ha presentado graves retos para la permanencia duradera, y cómo, las diferentes estructuras que fue dejando a su paso el necesario traslado de la población, hablan de otras tantas batallas perdidas entre sus pobladores y el medio. Por su parte, Quirec Chantraine, presenta un sugerente relato de la época de oro de los viajes transatlánticos, cuando la navegación a vapor hizo posible el movimiento masivo de personas y mercancías, y, por supuesto, el mundo comenzó a ser un entorno más pequeño en el que los grandes capitales se interesaban en invertir en los medios de transporte para hacer llegar a todo el orbe sus intereses. En ese mundo de la modernidad, caracterizado también por la entrada en vigor de los acuerdos que hicieron posible la Unión Postal Universal, que el puerto mexicano de Veracruz tuvo una participación importante al constituir la principal puerta de entrada a los nuevos flujos simbólicos procedentes de Europa y del mundo, pero también al permitir que de sus muelles salieran los bienes y también las imágenes que habrían de alimentar el estereotipo de lo mexicano.

Otro importante aspecto del libro que merece ser resaltado es el hecho de que representa una muestra de la riqueza de lecturas y contenidos historiográficos que se posibilitan a través de la afortunada conjunción del quehacer arqueológico e histórico. El tema, que ha sido ya motivo para dos congresos -uno de los cuales derivó en la edición que ahora nos ocupa-, promete mucho, ya que es incalculable el número de miradas que se pueden dirigir al mar como pretexto para visitar prácticas y representaciones que los sujetos de varias épocas y contextos han construido, en el entendido de que las relaciones humanas, elaboradas y compartidas socialmente son las que construyen los entornos y los paisajes; el mar posee siempre los atributos que los sujetos que entran en relación con él le atribuyen, y son éstos quienes, en contextos específicos, le dan sentido a su relación. 